\title{
LOS NOMBRES DEL INCONSCIENTE EN LA FILOSOFÍA GRIEGA
}

\author{
THE NAMES OF THE UNCONSCIOUS IN GREEK PHILOSOPHY
}

Belén Castellanos Rodríguez *

Resumen: Partiendo de nuestra tesis según la cual, la reformulación de Gilles Deleuze del Inconsciente recibido del pensamiento psicoanalítico es una reformulación presocrática, nos hemos propuesto indagar acerca de una idea tal en la filosofía griega. En ella encontramos la aparición de ciertas reflexiones ontológicas en torno a un pensamiento sin sujeto o alma preindividual, bajo el nombre de logos, nous, etc., según atendamos a Heráclito, Parménides, Anaxágoras... Platón y Aristóteles reciben la idea ontológica presocrática de pensamiento, dando lugar a dos derivas distintas que permiten entender el Inconsciente de un modo más esencialista o más constituyente, respectivamente.

Palabras clave: Deleuze, Inconsciente, presocráticos, logos, nous.

\begin{abstract}
Based on our view that the reformulation of the Unconscious Gilles Deleuze received psychoanalytic thinking is a pre-Socratic reformulation, we have decided to inquire about such an idea in Greek philosophy. In it we find the emergence of certain ontological reflections around a subject or thought without soul preindividual, under the name of logos, nous, etc.., As we attend to Heraclitus, Parmenides, Anaxagoras ... Plato and Aristotle are the ontological notion of pre-Socratic thought, giving rise to two different drifts that allow us to understand the unconscious in a more essentialist or more constituent, respectively.
\end{abstract}

Key-words: Deleuze, Unconscious, Presocratics, logos, nous.

Doctora en Filosofia. Investigadora en Euro-Mediterranean University Intitute, a la Universidad Complutense de Madrid, en los Departamentos History and Civilization y EuroMed: Equaliy and Gender Studies. Mienbro del Grupo de Investigación ONLENHER de la UNED (Departamento de Filosofía). m@il: belencastellanos@emui.ucm.es.

Problemata: R. Intern. Fil. Vol. 03. No. 01. (2012), pp. 96-124

ISSN 1516-9219.DOI: http://dx.doi.org/10.7443/problemata.v3i1.12228 


\section{Introducción: La perspectiva postestructuralista y presocrática de Gilles Deleuze.}

Con el presente artículo, tratamos de evidenciar la idea de Inconsciente como idea y no solo como concepto adscrito a una disciplina particular, óntica, como pudiera ser la psicología o la biología. Destacarla como idea implica perseguirla en el ámbito propio de la filosofía. Pero además, deseamos contemplar la idea de Inconsciente, rastreando sus distintas formulaciones desde los inicios de la filosofía, previas a las preocupaciones del hombre moderno. Hablar de los inicios de la filosofía significa convocar el espíritu de los primeros repertorios meditativos, significa viajar a Grecia e intentar conectar con sus personajes conceptuales $\mathrm{y}$, sobre todo, con los filósofos presocráticos. Hablar de los inicios de la filosofía consiste, asimismo, en rescatar la preocupación primera, la cuestión ontológica del arché, abordando preferentemente el problema del límite posibilitante o, si queremos, de las condiciones de posibilidad de todas las cosas. Desde esta perspectiva, deseamos ofrecer una posible lectura de la filosofía presocrática y de su recepción en Platón y en Aristóteles. Esta lectura estaría orientada a la búsqueda de la idea de Inconsciente como primer principio ontológico en los escritos presocráticos, aun cuando apareciera nombrado positiva y no negativamente, dando cuenta de porqué el romanticismo hubo de retomarlo bajo un substantivo privativo, es decir, como el reverso de la conciencia y no como dimensión directamente propositiva.

$\mathrm{Si}$ bien tal ejercicio de investigación textual aparece dotado de sentido completo por sí mismo y resulta de interés filosófico general, especialmente para los estudiosos de la antigüedad griega, ganamos en rigor si explicitamos cuál ha 
sido, en nuestro caso, el contexto más amplio de investigación y la motivación que, desde la inmersión en la filosofía postestructuralista, nos ha conducido al ámbito y al examen que presentamos. El discurso filosófico que está en el horizonte de nuestra comprensión es, como decíamos, el discurso del postestructuralismo pero abordado, a su vez, desde el interés por la recepción y crítica de los hallazgos y planteamientos del psicoanálisis. Así, las complejas relaciones entre psicoanálisis y postestructuralismo han resultado encontrarse a la base de ese viaje hacia la antigüedad, necesario, entendemos, para dilucidar de modo claro cómo esta última corriente recoge y reformula las ideas de inconsciente $y$ de deseo a partir de las sistematizaciones freudianas y lacanianas. El personaje conceptual que, preferentemente nos ha acompañado, es Gilles Deleuze, excelente interlocutor, crítico y filósofo del psicoanálisis, que hereda sus principales conceptos pero tratando de eliminar el carácter dialéctico y humanista que aún pervive en ellos a partir de reflexiones de enorme profundidad:

\begin{abstract}
No buscamos en Freud al explorador de la profundidad humana y del sentido originario, sino al prodigioso descubridor de la maquinaria del inconsciente, por la que el sentido es producido, siempre producido en función del sinsentido (Deleuze, 1969, p. 91).
\end{abstract}

Nuestra tesis principal, a la hora de comprender los avatares de la obra deleuzeana, consiste en afirmar que el progresivo distanciamiento respecto del concepto psicoanalítico de inconsciente, así como la permanente recuperación y reivindicación del Freud de Más allá del principio del placer, que comenzarían a ser central en Différence et répétition (Deleuze, 1968. p. 26 y ss) sobre otras derivas del neurólogo vienés, se hallan atravesados por la perspectiva del inmanentismo ontológico o espiritualismo transcendental (no transcendente) inspirado por la filosofía presocrática recuperada, quizás, a través de Nietzsche y, aun implícitamente, 
a través de Heidegger. Entendemos que, queriendo encontrar en el Inconsciente el primer principio ontológico, "el clamor del Ser" (en palabras de Badieu), Deleuze se dispone a postular un pensamiento sin sujeto, no consciente, pero ni siquiera antropomórfico, del cual los filósofos presocráticos dieron cuenta como nadie. Desde este lugar, Deleuze se encontrará en disposición de pervertir el platonismo en el seno del psicoanálisis, denunciando cualquier esencialismo con el que pudiera caracterizar el inconsciente.

Nuestro Deleuze es un Deleuze leído a través de LéviStrauss, no del de los universales sociológicos y de las estructuras invariantes (seguido en Lacan), sino, por el contrario, del Lévi-Strauss de la primacía de lo social, de lo social constituyente sobre lo cultural, sobre lo social constituido:

\begin{abstract}
No pretendemos, de ninguna manera, insinuar que transformaciones ideológicas engendran transformaciones sociales. El orden contrario es el único verdadero: la concepción que los hombres se forjan de las relaciones entre naturaleza y cultura es función de la manera en que se modifican sus propias relaciones sociales" (Lévi-Strauss, 1998. p. 173-174).
\end{abstract}

También creemos que Deleuze bebe, como los demás postestructuralistas, de una fuente común que es Althusser, del que heredan la comprensión de la subjetivación como fenómeno ideológico, la concepción del carácter construido de la sexualidad y de las pulsiones y, en definitiva, la concepción del Inconsciente y del deseo como productivos y políticamente constituyentes:

Cuando alguien $<<$ relata su vida $>>$ o describe sus sentimientos en una "situación vivida", o relata un sueño, etc., su discurso es informado por el discurso ideológico, por el "yo" que habla en primera persona, y 
por el sujeto ante quien habla y que es juez de la autenticidad de su discurso, de su análisis, de su honestidad, etc.; es informado también, en el mismo acto, por los significantes ideológicos... (Althusser, 1996. p. 124);

La estructura del discurso del inconsciente, sin embargo, es totalmente diferente de la estructura del discurso ideológico, puesto que no está centrada y el "sujeto" del inconsciente no figura en persona sino por "lugarteniencia" en el discurso del inconsciente (Althusser, 1996. p. 126).

A partir de este mimbre percibimos, delezeanamente, dos atolladeros importantes en el pensamiento psicoanalítico sobre el Inconsciente. En primer lugar, la primacía ontológica del Inconsciente sobre la conciencia no queda fijada correctamente puesto que aunque la conciencia y el yo sean presentados como efectos de superficie, Freud también se refiere al Inconsciente como continente de todo lo relegado por la conciencia como resto de las operaciones represivas y del olvido (Freud 2001, 308-330). En este punto se produce una petición de principio. Este planteamiento trae dos problemas: nos encadena a la dialéctica ley-deseo, es decir, a un deseo siempre perfilado por oposición a la ley y, por tanto, secundario e improductivo:

... cuando reducimos la producción deseante a un problema de fantasma, nos contentamos con sacar todas las consecuencias del principio idealista que define el deseo como una carencia, y no como producción... (Deleuze y Guattari, 1972. p. 33).

En segundo lugar Deleuze denuncia el culturalismo con el que el psicoanálisis carga al inconsciente. Si queremos hacer del Inconsciente primer principio, como a veces parece querer también el propio Freud, no puede ser representativo, simbólico, 
modélico, ni siquiera cualificable, si seguimos la condición de Anaximandro. A partir de nuestras investigaciones detalladas sobre su obra, encontramos en Deleuze la idea de un Inconsciente que posibilita la experimentación en lugar de hipotecarla con metas o modelos prediseñados, como quisiera un mal platonismo. Lacan, lejos de permitir una salida fuera del inconsciente arquetípicamente cargado, profundiza en el problema, aumentando el ensimismamiento y pesimismo político, tal y como indica Butler:

En Lacan lo simbólico se define en términos de una concepción de las estructuras lingüísticas que son irreductibles a las formas sociales que toma el lenguaje. De acuerdo con el estructuralismo, lo simbólico establece las condiciones universales bajo las cuales se posibilita la socializad, es decir, la comunicabilidad de toda una utilización del lenguaje (...) El punto de vista lacaniano insiste en que hay un ideal y una demanda inconsciente que se hace a la vida social que permanece irreductible a causas y efectos atribuibles socialmente. El lugar simbólico del padre no cede a las demandas de una reorganización social de la paternidad. En cambio lo simbólico es precisamente aquello que marca los límites de cualquier esfuerzo utópico de reconfigurar y de revivir las relaciones de parentesco a cierta distancia de la escena edípica (Butler, 2006. p. 74).

Dentro de este culturalismo que tratamos de denunciar, se encuentra la hipóstasis del esquema edípico como estructura de interpretación de lo individual y de lo social, que hunde ambas dimensiones en un familiarismo aparentemente irrebasable:

El psicoanálisis y el complejo de Edipo recogen todas las creencias, todo lo que ha sido creído en todos los tiempos por la Humanidad, pero para llevarlo al estado de una denegación que conserva la creencia sin creer en ella (...) Lo que queda al final es un teatro íntimo y familiar, el teatro del hombre privado, que ya no es ni producción deseante ni representación objetiva 
(Deleuze y Guattari, 1972. p. 362).

Esta es la crítica más explícita en Deleuze (Edipo, más que descubierto, es defendido por el psicoanálisis como conjunto de tendencias que, sublimadas, producen la cultura, es decir, las empatías y las identificaciones). Comprender la crítica de Deleuze al psicoanálisis, consiste, pues, en advertir su reivindicación presocrática de un arché, el Inconsciente, no moral ni político, no simbólico siquiera, que permitiría, por ello, el verdadero acontecer político, posibilitado, estéticamente, por la capacidad que nos brinda para percibir de otro modo, para deconstruir sentidos instalados, volver al sinsentido y desde él, fabricar nuevas perspectivas.

\section{Descubrimiento y denominación del Inconsciente.}

Si hemos de tratar el asunto del descubrimiento del Inconsciente o, si además, nos proponemos datarlo, especificar el origen de su conceptuación, debemos ser extremadamente cuidadosos, evitando que los nombres nos confundan respecto al lugar que determinadas referencias van ocupando en el pensamiento a lo largo de los tiempos. Podríamos entender vulgarmente que el Inconsciente se descubre en la modernidad o, más manifiestamente, en el romanticismo, y también que poco después Nietzsche lo aborda y lo quiere explícitamente y Freud lo sistematiza, lo problematiza y le da un desarrollo conceptual detallado y sofisticado. Sin embargo, no estamos hablando con demasiada propiedad cuando denominamos descubrimiento a este fenómeno. Hablar de descubrimiento de algo implica un total desconocimiento, a lo largo de toda la 
historia humana anteriormente registrada. Esto no es lo que ha ocurrido con el Inconsciente sino que, en todo caso, habrá que distinguir el momento del descubrimiento del momento de la denominación. Del mismo modo que Sócrates-Platón no descubren el sentimiento de comunidad y ciudadanía sino que, con su expresa e insistente mención y conceptuación, pretenden reconquistar algo que, de modo "natural" y "espontáneo", se daba y asumía antes de la introducción sofista del relativismo, los románticos, Nietzsche y Freud no descubren el Inconsciente sino que se esfuerzan en retomar algo que constaba ya en el pensamiento griego y cuya denominación o indicación explícita, mediante un privativo, no se hace necesaria ni seguramente pertinente, hasta la reducción cartesiana del Ser a la subjetividad y del sujeto a la conciencia. En este sentido se expresa Lancelot Law White cuando afirma:

Hasta que hizo un intento (con éxito aparente) para escoger la conciencia como la característica que define una manera independiente de llamar a la mente, no hubo ocasión para inventar la idea de la mente inconsciente como corrección provisional de esa selección. Solamente después de Descartes encontraremos la idea y luego el término "mente inconsciente" que entra a formar parte del pensamiento europeo. No había nada extraordinario en el criterio antiguo en el sentido de que los aspectos tanto divinos como físicos pudieran influir en la mente; esto sólo provocó alguna inquietud filosófica después que Descartes logró convertir a mucha gente a su punto de vista de que la mentalidad consciente debía separarse de todo lo demás (L. Law White, 1967. p. 37).

El giro de Descartes exige una corrección y Freud, sobre todo Freud, va a encargarse de hacerla, aun quedando constreñido al estrecho campo subjetivista en que Descartes encierra el problema ontológico. Tal vez por querer Freud 
resolver, ante todo, el problema cartesiano de la primordialidad de la conciencia, rebatiendo la autoevidencia del yo y la transparencia de la subjetividad para sí, queda preso, no obstante, del marco, de la localización particularmente cartesiana, una localización profundamente psicologista.

Si queremos rastrear en la filosofía griega algo que pueda prefigurar el concepto de Inconsciente con el que tan llamativamente Freud ha captado nuestra atención, y si, aún más, queremos encontrar una inspiración que lo salve de las constricciones psicologistas y nos permita desembocar en un abordaje del Inconsciente de interés ontológico, lo haremos, irremediablemente, desconectando del afán moderno de buscar siempre un decir sobre el hombre, sobre el sujeto, de buscar moralejas, sentencias, absoluciones o consuelos. Tratamos, más bien, de recuperar el espíritu del Heidegger de Tiempo y ser, su giro desde la metafísica del sujeto hacia la recuperación de una filosofía del Ser, a partir del cual, la filosofía no tiene por qué dar una guía para una vida feliz. Entendemos que la modernidad, a excepción quizás, de la filosofía propiamente barroca, se caracteriza por subordinar cualquier estudio verdaderamente ontológico a una teoría del conocimiento o a una filosofía de la mente que, además, condicionará ya cualquier disquisición acerca de la realidad, del objeto, de lo ente y también del Ser. El humanismo renacentista, en fricción con el antropomorfismo religioso, pasa a antropomorfizar la realidad entera, y también el pensar, profundizando en una especie de narcisismo, del que no saldría en mucho tiempo, y del que es aún deudor un cierto Freud judeo-platonizante. La visión panhumanista que se instaló en la tradición moderna occidental y que se radicalizó con la implantación del dispositivo tecnológico implica toda una teleología universal pensada a imagen y semejanza del hombre pragmático. No solo en Heidegger sino también en Deleuze encontramos bellas reescrituras del pensamiento presocrático, centrado no en lo 
específicamente humano sino vinculado a la co-pertenencia de Ser y Pensar. Esto es mucho más radical que decir que el Ser es el tema del pensar, ya que supone asumir con los presocráticos, que nous y, sobre todo, logos, no son la proyección ni la creación de un sujeto, sino que simplemente son. En este asunto nos puede resultar clarificadora la diferenciación spinozista. Recordemos que en las Cartas 51-56 a Boxel, Spinoza exponía que "el hombre piensa" y piensa en el sentido subjetivo de la autoconciencia, lo cual no sería propiedad absoluta de los modos del pensamiento, y por eso se aclara que el hombre, aunque especial, no es privilegiado ontológicamente. Este pensar suyo sería el "modo del pensar como proceso", siendo pensamiento noético, en la terminología spinozista. Por otra parte, dirá que en Dios se encuentran las ideas, lo cual implica que los pensamientos son racionales y constituyen el orden racional del mundo impersonal no pensado por un sujeto autoconsciente pero sí según un orden. Se habla aquí del pensamiento noemático. Esta diferenciación es la que hace problemática la articulación del modo infinito mediato, que Spinoza dejará vacío al no poderse encontrar en la subjetividad la totalidad actual de los modos del pensamiento. Podemos comenzar entonces la investigación del asunto que nos ocupa dejando a un lado cualquier privilegio ontológico concedido al hombre, lo cual no significa que no se considere como ente especial en tanto que es capaz de preguntar por el Ser. De esta manera estaremos mejor dispuestos a conectar con la filosofía presocrática. La pregunta que debemos plantear o que es posible formular a pensadores como Tales, Heráclito, Parménides, Empédocles, o Anaxágoras para que nos digan algo sobre eso que ahora denominamos Inconsciente, es la pregunta acerca de un pensamiento sin sujeto. 
3. El pensamiento sin sujeto: el logos y lo divino griego.

En Tales tan solo encontramos una frase bastante enigmática, según la cual todo está lleno de dioses. De esta forma parece atribuirse alma también a los seres inanimados. Kirk, Raven y Schofield interpretan esto en el sentido de que "el mundo como un todo manifiesta un poder de cambio y de movimiento que en verdad no es humano..." (Kirk, Raven y Schofield, 1994. pp. 148-149). Tales estaría en disposición de entender la diferencia entre alma humana y fuerza divina a pesar de advertir la conexión de la una con la otra, y esta última, la fuerza divina, ese alma que está en todas las cosas podría prefigurar el concepto de logos en tanto que pensamiento sin sujeto que hace presencia también, pero no primariamente, o no causalmente, en el espíritu humano. Esta vibración puede recorrerle a nivel inconsciente, tomando carácter reflexivo solo en el proceso del conocer (recordar, esquematizar, objetivar, conceptuar...).

Sin embargo, de entre los presocráticos, será Heráclito el pensador protagonista e indispensable para nuestra búsqueda. En Heráclito se bosqueja, sin duda, la idea de un pensamiento sin sujeto, que el espíritu humano debe tratar de comprender. El logos es ese pensamiento sin sujeto, el (des)orden común que rige todas las cosas. Ese logos no es un elemento de la consciencia, sino que, en todo caso, está a la base de ésta y se oculta tras ella como se oculta tras las cosas. El logos es el límite que posibilita el pensamiento y su subjetivación y, así, lo tomamos como el precedente fundamental para la elaboración del concepto de Inconsciente ontológico, o lo que es lo mismo, del Pensar del Ser o del Pensar-Ser, tal y como lo expresa siempre Martin Heidegger. Veámoslo en las propias palabras de Heráclito: 


\begin{abstract}
Siempre se quedan los hombres sin comprender que el Logos es así como yo lo describo, lo mismo antes de haberlo oído que una vez que lo han oído; pues, aunque todas las cosas acontecen según este Logos se parecen los hombres a gentes sin experiencia, incluso cuando experimentan palabras y acciones tales cuales son las que explico, cuando distingo cada cosa según su constitución y digo cómo es; al resto de los hombres les pasan desapercibidas cuantas cosas hacen despiertos, del mismo modo que se olvidan de lo que hacen cuando duermen (Fr. 1, Sexto, adv. math. VII 123 en Kirk, Raven y Schofield, 1994. p. 273).
\end{abstract}

Con sus lúcidas palabras, Heráclito nos transmite la idea de un pensar, que es un Pensar del Ser, es decir, que da cuenta del Ser, de su acontecer, de su ser siendo como fuere sin el consentimiento del esquematismo humano. Pero así como da cuenta del Ser, inversamente, lo posibilita ya que según ese logos ocurren las cosas. Caeríamos en el absurdo, o al menos en un anacronismo imperdonable, si, al mismo tiempo, quisiéramos que ese logos fuera el pensamiento de la conciencia individualautónoma. Más bien el logos sería un Otro de la conciencia que discurre y en virtud del cual ésta discurre. El logos es Uno (aunque Uno no numérico o al menos no numérico cardinal) en el sentido de que es principio constituyente pero es, asimismo, plural en la medida en que es principio diferenciador. En cuanto que principio constituyente es el límite común e indemostrable (o solo mostrable en función de la refutación por absurdo de cualquier postulado que lo niegue) a partir del cual se es y se piensa. En cuanto que principio diferenciador reafirma la pluralidad, no devenida, sino constituyente, que reina desde el punto de vista modal. Y todo ello sería así aún cuando permanece oculto y ajeno al reconocimiento humano ya que, incluso el ser del humano, halla su principio constitutivo fuera de sí mismo, en una heteronomía que está más allá de su 
consentimiento y determinado por la cual es, vive, actúa y piensa. En este sentido creemos entender la afirmación de que "La auténtica naturaleza de las cosas suele estar oculta" (Fr. 123, Temistio, Or. 5, pág. 69 D, en Kirk, Raven y Schofield, 1994. p. 280). En función de lo expuesto, advertimos la presencia de una instancia susceptible de ser comprendida bajo el concepto de Inconsciente, en el pensamiento heraclíteo, a condición de reivindicar tal Inconsciente como innegablemente ontológico y libre de supuestos psicologistas. Faltaría, en estos momentos, preguntarnos, cuál es, para el filósofo de Éfeso, el lugar del Inconsciente (entendiendo lugar sino como plano de convergencia o espacio topológico de reunión). Antes de contestar a la pregunta oigamos a Heráclito:

Por tanto es necesario seguir lo común, pero aunque el Logos es común, la mayoría vive como si tuviera una inteligencia particular (Fr. 2, Sexto, adv. math. VII 133, en Kirk, Raven y Schofield, 1994. p. 273).

Desde el agenciamiento del pensador griego se nos impone una respuesta que pasa por asumir como lugar del Inconsciente, bien la virtualidad contrafáctica, bien la Comunidad. Sin embargo, a pesar del aparente dilema, vamos a recoger ambas posibilidades como incluyentes, sobre todo porque ello nos permite un buen boceto para el planteamiento de una ontología política que, siguiendo el estilo griego, sea capaz de evitar el presentismo en la precisa medida en que el marco de la Comunidad como contexto del pensar atesora, por un lado, el saber referido a un Ser que nunca es agotado por la existencia y, con ello, por otro lado, las potencias revolucionarias del desorden y el reorden que, en sus múltiples jugadas, convocan (o apuestan por) el acontecer del Ser a través de los diferentes mundos. Lo que no parece encontrar 
consistencia sería un pensar autónomo-individual de la conciencia particular, ajena a un genuino pensamiento griego, ya que desde éste, tal pensar no daría cuenta del alma:

"No llegarías a encontrar, en tu camino, los límites del alma, ni aun recorriendo todos los caminos: tan profunda dimensión tiene" (Fr. 45, Diógenes Laercio, IX 7, en Kirk, Raven y Schofield, 1994. p. 297).

Para dar cuenta del alma se hace necesaria una apertura experiencial en el sentido empírico transcendental que reivindica Deleuze y como leemos en el brillante presocrático:

\begin{abstract}
Mas, durante la vigilia, se asoma de nuevo a través de sus canales perceptivos como si fueran ventanas y tomando contacto con lo circundante se reviste de su poder de razón (Sexto, adv. math. VII 129 (DK 22 a 16, en Kirk, Raven y Schofield, 1994. pp. 299-300).
\end{abstract}

El logos no tiene sujeciones sino que hombres y dioses son inteligentes, autoconscientes y personas en la medida en que participan o, mejor dicho, están, en el logos, que une a los hombres en una comunidad de significados, siendo la racionalidad la fraternidad con la naturaleza.

\title{
4. El Pensar del Ser como pensar no humano.
}

Para la búsqueda del Inconsciente en el pensamiento 
parmenídeo, tomemos de nuevo la orientación de Heidegger, excepcional transmisor del pensamiento de Parménides, según el cual, lo mismo es Ser y Pensar. A partir de esta mismidad se hace posibleel encuentro con unos precedentes griegos suficientemente claros para el concepto de Inconsciente. Baste recordar las siguientes palabras de Parménides:

\footnotetext{
Por ello es correcto que lo que es no sea imperfecto; pues no es deficiente -si lo fuera, sería deficiente en todo. Lo mismo es ser pensado y aquello por lo que es pensamiento, ya que no encontrarás el pensar sin lo que es en todo lo que se ha dicho (o "en lo que se expresa el pensamiento")... (Fr. 8, 32-49, Simplicio, in Phys. 146, 5, en Kirk, Raven y Schofield, 1994. pp. 362-363).
}

Esta mismidad entre el Ser y el Pensar podría expresarse en términos hegelianos: "lo real es racional y lo racional es real". Sin embargo, vamos a escoger una asunción más heideggeriana o una más postestructuralista, tanto más cercana, en cualquier caso, al espíritu griego y tanto más productiva para mostrar una comprensión ontológica del Inconsciente. Si en el agenciamiento hegeliano de Parménides había una yuxtaposición a partir de la cual el Pensar se imponía progresivamente por encima del Ser, como desenvolvimiento del Espíritu que conquista el para-sí, logrando finalmente su absoluta dominación y borrándose, en esa medida, la diferencia entre Ser y Pensar, al modo de una reconciliación, nuestro punto de partida postestructuralista nos lleva a repensar a Parménides de acuerdo a la co-pertenencia entre el Ser y el Pensar, libre de síntesis que no sean disyuntivas. Cuando decimos con Parménides que lo mismo es Ser que Pensar no tratamos de afirmar que haya una identificación o una subsunción conceptual del uno en el otro, sino que se condicionan y se posibilitan mutuamente, sin ser ninguno anterior respecto del 
otro. Creemos que esta co-pertenencia expresa, mejor que ninguna otra fórmula, la rotundidad de la inmanencia que presidirá el pensamiento de muchos de los más notables pensadores, incluyendo, por supuesto, y de una forma especial, a Gilles Deleuze. Para encontrar certeramente el saber de la inmanencia en el Ser-Pensar del Eléata, necesitamos reconocer dos condiciones: la primera consiste en cifrar el Pensar en un pensamiento sin sujeto, tal y como, por otra parte, había sugerido Heráclito, siendo entonces un pensamiento extático, noemático, posibilitante: Inconsciente cuya subjetivación supondría un punto de llegada y no de partida; y la segunda consiste en recordar una vez más que el Ser es el Uno no numérico y no extenso sino intensivo y plural, tal y como le corresponde a toda unidad cada vez que la entendemos como reunión de multiplicidad. Si el Ser fuera extensión, el Pensar del Ser sería conquista y apropiación, tal y como parece querer la filosofía dialéctico-hegeliana. Sin embargo, el Ser constituye, no la posesión de la totalidad, sino la ley ontológica que divide y reúne. Del mismo modo, Ser y Pensar son condicionantes de la formación y aparición del ente y del momento reflexivo que conduce al brotar de la conciencia, respectivamente. Y, en este sentido, podríamos decir, con Deleuze, que el Inconsciente maquina deseo, energía de deconstrucción y reconstrucción, de caos y de cosmos. El Pensar en la concepción de Hegel no es el pensar como límite posibilitante puesto que, por el contrario, sería un Pensar que no deja ser al Ser, que lo oprime en un movimiento de autorreflexión. Sin embargo, difícilmente podemos acordar con Hegel que hallemos en este proceso la operación del conocimiento, puesto que un pensar tal, que enfrentara a la physis como a un enemigo, ya no sería un Pensar sino un dominar que niega la heteronomía sin la cual no se daría aprendizaje, influencia, alteridad... Así, lo que es, entendemos desde el postestructuralismo, es necesariamente pero no según una finalidad, no determinado por un orden preestablecido que 
se despliega hacia un punto o hacia una meta. Parménides ha descubierto la ley del Ser-Pensar en el ámbito de la verdad ontológica: en la aletheia se entregan y apropian mutuamente Ser y Pensar, vibrando, pues, el Inconsciente en los sujetos de una comunidad, que no serían sujetos sino en función de este pliegue del Inconsciente, que constituye un exterior y un interior comunicantes. Estas apreciaciones, tal vez no serían posibles sin la fuga de Heidegger respecto de la mentalidad moderna, operación que le permite un rememorar, un pensar lo no pensado desde lo pensado (Oñate, 2009. p. 94). Toda aletheia, como tal, es siempre una interpretación histórica, ni arbitraria ni definitiva, pero que, además, no es histórica en el sentido dialéctico de parcialidad. Se trata más bien de un límite semejante al de Spinoza, en el que lo no conocido es tan importante como lo conocido y nunca se conquista puesto que el conocimiento de los modos no agota la substancia. La natura naturans es el límite porque carece de causas finales y no se puede antropomorfizar: no hay en ella bondad ni maldad, ni belleza ni fealdad. Pero solo a partir de ese límite, de ese retraimiento del Ser (que otorga un nuevo sentido a la represión primaria), se nos desvela el don de lo que se da a la presencia. En los presocráticos, los mortales descubren lo divino, que es lo eterno y necesario, no siéndolo ellos mismos y asumiéndose como mortales. Precisamente en la admisión del no saber sobre lo Otro está el único origen posible de cualquier saber racional crítico, de cualquier vivir estéticamente, poéticamente, prescindiendo de la pretensión de erradicar el misterio, la muerte, el Inconsciente.

5. El nous como espiritu aconsciente y preindividual. 
Anaxágoras afirma lo siguiente acerca de la Mente:

es infinita, autónoma y no está mezclada" y que de entre las cosas "es la más sutil y la más pura de todas; tiene el conocimiento todo sobre cada cosa y el máximo poder (...) gobierna todas las cosas que tienen vida (...) conoce todas las cosas mezcladas, separadas y divididas (...) ordenó todas cuantas cosas iban a ser, todas cuantas fueron y ahora no son, todas cuantas ahora son y cuantas serán (Fr. 12, Simplicio, Fís. 164, 24 y 156, 13, en Kirk, Raven y Schofield, 1994. pp. 507-508).

Parece difícil suponer que tal mente sea la de un sujeto o la de una conciencia. Tampoco parece plausible la idea de que sea concebida como algo transcendente, si bien se formula en términos transcendentales (buscando las condiciones de posibilidad):

Pero la Mente, que siempre es, está ciertamente ahora incluso donde están también todas las demás cosas, en la masa circundante y en las cosas que han sido unidas o separadas ( Fr. 14, Simplicio, Fís. 157, 7, en Kirk, Raven y Schofield, 1994. p. 509).

Releyendo con atención las observaciones de Anaxágoras vemos que, de nuevo, se cumplen todos los requisitos que nos permiten hablar de un pensamiento sin sujeto, cosa que, a su vez, posibilita la asignación del estatuto del Inconsciente. Por un lado, la mente, tal y como la presenta el filósofo de Clazomene, tiene el carácter divino, por cuanto reúne y divide el tiempo, siendo su propio tiempo el Aion y no el Cronos, y en la medida en que se sitúa más allá de lo humano. De la misma manera, se formula, por definición, como inmanencia, puesto que está en las propias cosas, no siendo exterior a ellas, sin por ello quedar atrapada en cavidad interna alguna, tal y como 
requeriría una autoconciencia. Añadamos además, que es Una y múltiple, ya que siendo substancia pura y por sí misma, se halla en la "masa circundante" y en todas las cosas distintas. Trátase del Pensar en cuanto que co-perteneciente al Ser o, dicho de otro modo, es el Pensar del Ser en una concepción libre de dualismos mente-cuerpo, más cercana a la visión espiritualizada del último, condicionando así la aparición del proceso de conocimiento dentro de la esfera de lo animado, en lo cual se oculta y manifiesta. Por ello, decimos que es principio heterónomo de la subjetividad y arché en general, primer principio ontológico y no psicológico, contrafáctico y no existencial, intenso y no extenso. Así, concluimos en aceptar que si podemos hallar una preformulación del Inconsciente en la filosofía presocrática será en el sentido de un pensamiento sin sujeto que condiciona los procesos de subjetivación y que no es irracional, hablando rigurosamente, sino, en todo caso, sinsentido, en cuanto que indemostrable, incausado, inocente. Así, creemos que lo acoge Nietzsche, Deleuze e incluso cierto Freud (el Freud de Más allá del principio del placer) cuando lo mencionan explícitamente como Inconsciente.

\section{El arché modelico platónico y el Inconsciente arquetípico.}

Convendría ahora seguir el rastro retroactivo del concepto implícito de Inconsciente en Platón. Para no perder el hilo de la historia estrictamente filosófica, decimos, solo de modo muy breve, que en los sofistas, tal vez debido a su excesivo psicosociologismo, no encontramos ningún hilo, lo suficientemente oportuno, con el que enganchar la reflexión presocrática (o preplatónica) en torno a la cuestión de un pensamiento sin 
sujeto. En cambio, sí percibimos, bajo su escepticismo social y, más concretamente, flotando entre sus loas a la demagogia, entre el nihilismo de Gorgias y su condena lapidaria al lenguaje y a la palabra, una intuición, tal vez inconsciente, del vagabundeo del Inconsciente, entendiendo su imperio como negativo, como imperio del deseo anulador de toda razón. Toda la temática sofística, que vincula discurso y poder, oratoria y areté, persuasión y democracia, parece fundamentarse en una teoría sobre la sugestión, el contenido velado del discurso y la imposibilidad del acuse de recibo en el terreno de la comunicación humana, cuyo elemento básico debería ser precisamente el inconsciente $\mathrm{y}$, de hecho, un inconsciente al estilo freudiano de Psicología de las masas y en la onda de todo lo que compone la preocupación lacaniana principal.

Cuando llegamos a Platón, la senda presocrática queda desenfocada y el camino hacia la preformulación del Inconsciente ontológico, se enreda en las fabulaciones del alma individual, torciéndose por ello hacia la formulación latente de un inconsciente psicológico (sobre todo si atendemos al Platón transmitido por la tradición vetotestamentaria). Podemos decir que la teoría de la reminiscencia y el método mayéutico, suponen la idea o, al menos, la preconcepción, de la existencia de contenidos inconscientes al estilo freudiano. Mientras Platón adolece de la necesidad mitológica de plantear la inmortalidad de un alma individual (aunque no explicite en qué medida y modo se conservaría la llamada "personalidad"), Freud nos deja, en su lugar, un incómodo interrogante sobre la posibilidad de una herencia filogenética de los contenidos inconscientes, o de su simbolismo, o de su supuesta gramática. Además, en Platón, esos contenidos inconscientes son pensados bajo el modelo de la conciencia e incluso de una conciencia superior matemáticoracional, olvidada por, o dormida en, el individuo a causa de su alienación en el cuerpo, que le impone pensamientos ajenos, servidumbres a la realidad material. Por el contrario, hay 
muchas razones para rastrear el inconsciente freudiano en el cuerpo y hallar en él una realidad que para nada remite a una pureza perdida. Conviene señalar que si queda cierto platonismo (o mejor dicho, cierto mal platonismo) a combatir en el interior de Freud, está, en todo caso, mucho más presente en Jung, en el que la teoría de la metempsicosis, de la inmortalidad y de la divinidad transcendente, parece seguir teniendo un lugar (Myss, 2002. pp. 124-125; Meslin, 1978. p. 212; Kerényi, 1994). Lejos de hallarnos ante una teoría de base más social (y no culturalista), cuando nos enfrentamos con el inconsciente colectivo de Jung, tenemos la impresión de encontrarnos con una nueva mistificación, en la que la metafísica platónicamonoteísta cobra especial fuerza. Los elementos propios de un inconsciente así pensado serían lo que Jung dio en llamar "arquetipos", imágenes del pensamiento que, aunque culturalmente desenvueltas, responden a un carácter universal. Usando el lenguaje junguiano, los arquetipos son posibilidades heredadas de representación (Jung, 2002. pp. 65-66 y 136). De este modo, podemos observar en este psicoanalista una especial fijación acrítica con algo que en Freud solo se presentaba como débil posibilidad y, en todo caso, como problema o límite de su propio sistema teórico: la herencia filogenético del lenguaje simbólico del inconsciente y la posibilidad de traducción, de representación del mismo a través de una serie de significaciones constantes.

Desde otro punto de vista, debemos hacer justicia a Platón, al menos en el esfuerzo de mostrar otras lecturas que no comprometen la preconcepción platónica de inconsciente con el intelectualismo mitológico del alma vagando por el mundo inmutable de la antigua geometría. En este sentido, pensadores como Maritain, se refieren a un protoconcepto platónico de inconsciente ligado al mundo de la locura, a la vida pasional, a la musa de los poetas, al pensamiento que se situaría por encima del lógico-racional: 
en efecto, el concepto de la musa para Platón está ligado al de pasión, al de manía, locura y delirio (cual los juegos pueriles), es decir, a la vida del inconsciente. Platón no cesa de ensalzar la manía o delirio, ese entusiasmo que anula la reflexión y el pensamiento lógico considerándolo como don supremo de los poetas... (Maritain, 2004. p. 142).

Sin embargo, si bien Maritain encuentra en Platón esa intuición del inconsciente, que, en tanto que ligada a la reflexión sobre la belleza, estaría ausente, para el filósofo católico, en los filósofos presocráticos y en Aristóteles, no nos parece tan claro que de la generalidad de la obra platónica se desprenda una valoración netamente positiva de los poetas, en cuanto que la relación de éstos con la puesta de la verdad es tratada de modo bastante ambivalente. En cualquier caso, Maritain se refiere al hallazgo platónico de lo que él denomina "inconsciente espiritual", distinto del objeto de los psicoanalistas (inconsciente irracional), raíz de la inteligencia, de la voluntad, de la libertad personal, que lucha por conocer, que puede aparecer mezclado con la sin razón y cuyo cometido es deshacerse de ésta para purificarse y encontrar la paz. De hecho, Maritain no solo encuentra ese inconsciente mítico-escatológico en Platón sino que trata, por todos los medios, de hacer uso católico del mismo.

Si mantenemos aún la empresa de invertir el platonismo en el psicoanálisis es porque consideramos que, aun asumiendo las sentencias de Althusser en relación a la disparidad existente entre el inconsciente objeto de estudio del psicoanálisis, y el inconsciente que, al menos desde Platón, ha rondado entre las preocupaciones filosóficas, Deleuze es heredero de ambas tradiciones, así como el propio Althusser, y todavía encuentra en el seno del psicoanálisis, en su teoría y en su metodología, elementos platonizantes, como pueda ser la idea de la cura a 
través del conocimiento, la fortificación de la idea de sujeto frente a un mundo, incluido el cuerpo, que sería objeto, la idealización del diálogo como puente comunicacional efectivo, la hipostatización de la gramática sobre el pensamiento, el problema de la participación, etc.

\section{La reinvención de los presocráticos y el nous poietikos.}

En Aristóteles podemos reencontrar ciertas resonancias presocráticas, colocándonos de nuevo en la línea de un pensamiento sin sujeto, o que es anterior o exterior a éste. Además de heredar el concepto de nous de Anaxágoras, explorado aquí anteriormente, Aristóteles habla más claramente de un nous poietikos eterno y presubjetivo que, en todo caso, estaría a la base del proceso de subjetivación individual. Este nous poietikos no está en el individuo al modo de propiedad sino que supone la condición de posibilidad del pensar y del conocer:

Así pues, existe un intelecto que es capaz de llegar a ser todas las cosas y otro capaz de hacerlas todas; este último es a manera de una disposición habitual como, por ejemplo, la luz: también la luz hace en cierto modo de los colores en potencia colores en acto. Y tal intelecto es separable, sin mezcla e impasible, siendo como es acto por su propia entidad. Y es que siempre es más excelso el agente que el paciente, el principio que la materia. Por lo demás, la misma cosa son la ciencia en acto y su objeto. Desde el punto de vista de cada individuo la ciencia en potencia es anterior en cuanto al tiempo, pero desde el punto de vista del universo en general no es anterior ni siquiera en cuanto al tiempo: no ocurre, desde luego, que el intelecto intelija a veces y a veces deje de inteligir. Una vez separado es sólo aquello que en realidad es y únicamente esto es 
inmortal y eterno. Nosotros, sin embargo, no somos capaces de recordarlo, porque tal principio es impasible, mientras que el intelecto pasivo es corruptible y sin él nada intelige (Aristóteles, 1978. Libro Tercero, V).

Por otra parte, el acto de pensamiento y el acto cognoscitivo no son procesos dialécticos en el sentido de que no culminan en síntesis alguna, dado que se trata de sucesos incorpóreos. El pensamiento y el conocimiento son distintos de la nutrición, en la medida en que dejan ser, no fagocitan, no se apropian de aquello que es pensado o de aquello que es conocido. El pensamiento, entonces, supone una unidad que no es una síntesis sino una apertura, un "salirse de sí" que no implica alienarse en el objeto conocido. Así, Aristóteles se desmarca de la imagen totalitaria del conocimiento como dialéctica entre sujeto y objeto. El acto de pensar y de conocer está fuera del sujeto y del objeto, siendo, por tanto, de tipo extático. El sujeto y el objeto serían, tan solo, categorías correspondientes al surgimiento de la conciencia y solo en este bucle autorreflexivo, tendrían sentido, como asunción de la intencionalidad y como modo, consiguientemente, del pensamiento intencional (Aristóteles, 1978. Libro Segundo).

En Aristóteles advertimos la idea de que no todo conocimiento o pensamiento es consciente, en cuanto que, ni tan siquiera toda percepción es consciente, indicando esto que los deseos, razonamientos o condiciones que se encuentran a la base de la percepción no consciente, serían, asimismo, inconscientes. Lacan trató de agenciar este entramado aristotélico reafirmando que hay conocimientos que pertenecen a lo Real, aunque no sean subjetivados por nadie. Éstos serían análogos a la Lógica, que Lacan la caracteriza como ciencia de lo Real, es decir, aquella que no tiene contenido o, mejor, que no tiene términos verificables sino que da cuenta únicamente de 
las relaciones previas al establecimiento del sentido. Ese sería el único mapa posible del inconsciente, del saber del inconsciente (Lacan, 1989).

En cualquier caso, estas aprecieciones que hemos hecho en torno a Aristóteles no solo arrojan luz en la persecución conceptual-histórica del Inconsciente, sino que nos permiten presenciar a un Aristóteles quizá más consistente que el tradicional y más coherente en su crítica del transcendentalismo platónico, en la medida en que podemos reinterpretar dos cuestiones relativas a su filosofía. En primer lugar, conseguimos apartar la concepción del acto puro, de ese primer motor inmóvil e inmaterial que, como tal, mueve sin ser movido pero no por contacto (en tanto que lo inmaterial no contacta), de cualquier idealismo platónico o de cualquier realismo de las Ideas, también platónico. Consideramos el acto puro como ese deseo extático, condición de posibilidad del movimiento, es decir, aclaramos que lo que mueve es el deseo, los deseos en cuanto que atravesados por ese Pensar del Ser, que podemos denominar "deseo" o Inconsciente. En segundo lugar, y a consecuencia de lo anterior, resolvemos otra dificultad en la interpretación de Aristóteles. Resultaba molesto, encontrar en un filósofo materialista, en sentido griego, en el mejor de los sentidos, una visión teleológica del mundo, en tanto que parecía, indirectamente, implicar una conciencia o supraconciencia, que entendida hegelianamente, moviera al mundo hacia su desarrollo predeterminado. Una teleología tal, sería de suyo, teológica pero en el sentido medieval. Sin embargo, nos podemos hacer cargo de otra teleología, la aristotélica, libre de las cargas tomistas. Esto se produce a condición de situar el telos a nivel de Inconsciente, procediendo inconscientemente $\mathrm{o}$, lo que es lo mismo, significando deseo, deseo-juego, deseo heraclíteo, deseo dionisiaco, deseo que deconstruye y reconstruye distintos planos de organización, animando inmanentemente al mundo. Liberamos así, al 
transcendentalismo de lo transcedente y reformulamos a Aristóteles como materialista transcendental, como materialista que se hace cargo de las condiciones de posibilidad. Es este el sentido en que Aristóteles reescribe a Anaximandro, reintroduce el apeiron y lo anima o lo presenta animado por el deseo. Telos, pues, dejaría de referir, como alerta Heidegger, a algún tipo de meta o finalidad, para significar rotundamente acabamiento, éxtasis, beatitud, no carencia (Heidegger, 2001, p. 15) . Telos, entonces, coincidiría, en su expresión plena, con el Ser, con el principio primero y constituyente que no puede albergar el noser, como exige la condición parmenídea.

Configuremos ya al final del presente escrito a modo de conclusiones. Para ello, nos vemos obligados a retomar aquel que habíamos advertido como horizonte y motivo de nuestra investigación: la reproposición presocrática del Inconsciente por parte de Gilles Deleuze. La compleja operación delezeana sobre las ideas de Inconsciente y de deseo tiene como propósito liberarlas de un esencialismo que hemos decidido denominar "esencialismo arquetípico", esencialismo que encontramos en el culturalismo psicoanalítico, en la universalización de estructuras sociales y de pensamiento que, con Deleuze, consideramos transitorias en tanto que producidas socialmente (diferenciación binaria de los sexos, estabilización de las relaciones de parentesco...), esencialismo que encontramos, finalmente, en el inmovilismo político que se deriva de todo ello al entender que el Inconsciente y el deseo, causas primeras de todo hacer y pensar, están estructurados según una Ley universal, que delimita las posibilidades de configuración social (1972). Deleuze cambia de base filosófica, girándose hacia perspectivas más materialistas o, si se prefiere, más inmanentistas, desde las cuales combatir el esencialismo con las armas de la ontología. Desde esta otra filosofía, Deleuze se propone alcanzar una concepción radical del Inconsciente como lo totalmente otro respecto de la conciencia, saliendo así de la reducción 
psicologista y pudiendo hallar en el Inconsciente un pensamiento sin sujeto, preindividual. Del mismo modo, Deleuze comprende el deseo como actividad que se hace posible desde el horizonte de ese Inconsciente. El deseo sería, así, productor de nuevas perspectivas, permitiendo la reunión de los opuestos, de lo diverso, bajo diferentes composiciones, permitiendo la construcción y deconstrucción de diferentes mundos y de diferentes modos del pensamiento. Por eso dice Deleuze que el deseo es rizomático y constituyente, porque conecta lo heterogéneo sin totalizarlo ni estabilizarlo (Deleuze y Guattari, 1980. p. 27). Un deseo políticamente constituyente implica la comparecencia del Inconsciente como primer principio ontológico, equivalente al Pensar del Ser del que hablaba Heidegger rememorando a los presocráticos en su escrito de 1951, "Logos" y a lo largo de Tiempo y ser (Heidegger, 2001, 1999). La equivalencia la encontramos fácilmente en el logos de Heráclito, que es un pensar asubjetivo, sin sentido o punto cero del sentido, que es el desorden de la Naturaleza u orden no antropomórfico. Lo que interesa resaltar, para comprender a Deleuze desde la tradición griega, es que este logos no tiene carácter moral ni político y justamente por eso posibilita el proyecto político, posibilita el verdadero acontecer político, en la medida en que no constriñe la acción política, no la sobredetermina con ninguna estructura, meta o Bien o Justicia moral preestablecida. Con su reproposición del Inconsciente, Deleuze entra a formar parte de la historia de la diferencia ontológica, que distingue las configuraciones transitorias, del arché que está a la base de todas ellas y que solo avistamos o precomprendemos en los procesos deconstructivos de tales configuraciones (Deleuze, 1968. pp. 24-25). Nosotros encontramos en Deleuze la salida definitiva del cristianismo: del alma individual del pecado y la culpa. Encontramos un Deleuze enfrentado al monoteísmo, que redescubre el nous poietikós de Aristóteles o alma preindividual, heredada del pensamiento 
presocrático del que el propio Aristóteles es receptor. Esta reivindicación aristotélica lubrifica, creemos, la perversión del platonismo en el seno del psicoanálisis, tal y como es el nietzscheano deseo de Gilles Deleuze.

\section{Referencias bibliográficas}

Althusser, L. comp. (1996) Escritos sobre psicoanálisis. Freud y Lacan. México: Siglo XXI.

Aristóteles. comp. (1978) Acerca del alma. Madrid: Gredos.

Bataille, G. comp. (2007) El erotismo. Barcelona: Tusquets.

Butler, J. Comp. (2006): Deshacer el género. Barcelona: Paidós.

Burk, I. (1966) Breve historia de la psicología: De los orígenes a Wundt. Caracas: Instituto Pedagógico.

Rof Carballo, R. (1964) Medicina y actividad creadora. Madrid: Cuadernos de Occidente.

Deleuze, G. (1962) Nietzsche et la philosophie. Paris: Presses Universitaires de France.

Deleuze, G. (1968) Différence et répétition. Paris: Presses Universitaires de France.

Deleuze, G. (1968) Spinoza et le problème de l'expression. Paris: Les Editions de Minuit.

Deleuze, G. (1969) Logique du sens. Paris: Les Éditions de Minuit.

Deleuze, G. (1990) Pourparlers. Paris: Les Éditions de Minuit.

Deleuze, G. (2003) Deux régimes de foux. Paris: Les Éditions de Minuit.

Deleuze, G. comp. (2004) Foucault. Paris: Les Editions de Minuit.

Deleuze, G y Guattari, F. (1972) L'Anti-Oedipe. Paris: Les Éditions de Minuit.

Deleuze, G y Guattari, F. (1980) Mille plateaux. Paris: Les Éditions de Minuit.

Derrida, J. comp. (2006) Márgenes de la filosofía. Madrid: Cátedra.

Freud, S. comp. (2001) Introducción al psicoanálisis. Madrid: Alianza.

Freud, S. comp. (1999) Esquema del psicoanálisis y otros escritos de teoría psicoanalítica. Madrid: Alianza.

Freud, S. comp. (1990) Psicología de las masas. Madrid: Alianza.

Guadalupe de la Mora Ledesma, J. (1981) Esencia de la filosofía de la educación. Moscú: Progreso.

Guattari, F. (1979) L'inconscient machinique: essais de schizo-analyse. Paris: Recherches.

Heidegger, M. comp. (2001) Conferencias y artículos. Barcelona: Serval.

Heidegger, M. comp. (1999) Tiempo y ser. Madrid: Tecnos.

Jung, C. G. comp. (2002) Los arquetipos y lo inconsciente colectivo. Madrid: 
Trotta.

Kerényi, K. (1994) Arquetipos y símbolos colectivos. Barcelona: Anthropos.

Kirk, G. S., Raven, J. E., Schofield, M. (1994) Los filósofos presocráticos. Madrid: Gredos.

Lacan, J. comp. (1989) Seminario 20. Aún. Buenos Aires: 1989.

Law White, L. comp. (1967) El inconsciente antes de Freud. México: Joaquín Mortiz.

Lévi-Strauss, C. comp. (1997) El pensamiento salvaje. México: FCE.

Lévi-Strauss, C. comp. (1998) Las estructuras elementales del parentesco. Barcelona: Paidós.

Meslin, M. (1978) Aproximación a una ciencia de las religiones. Madrid: Cristiandad, Madrid.

Myss, C. M. (2002) El contrato sagrado. Madrid: Javier Vergara.

Oñate, T. (2009) Materiales de ontología estética y hermenéutica. Los hijos de Nietzsche en la postmodernidad I. Madrid: Dykinson.

Sauvagnargues, A. comp. (2006) Deleuze. Del animal al arte. Buenos Aires: Amorrortu.

Singer, I. (1992) La naturaleza del amor. Vol I, De Platón a Lucero. México: Siglo XXI.

Spinoza, B. comp. (1987) Ética. Madrid: Alianza. 